\title{
28. A Chromosome Study in a Case of Klinefelter's Syndrome Associated with Diabetes Mellitus and Polycythemia Vera
}

\author{
By Eiji Hoshino, Noriko Nakada, Kazuyuki IshitobI, \\ Masaki Yamashita, and Yoshimichi HaradA \\ Department of Internal Medicine, Tottori University \\ School of Medicine, Yonago 683 \\ (Communicated by Sajiro Makino, M. J. A., May 12, 1982)
}

It has been known that Klinefelter's syndrome is associated occasionally with myeloproliferative disorders, particularly in a majority of cases with different forms of leukemia. The literature refers to only one case of polycythemia vera in association with this syndrome (Geraedts et al., 1980). In this paper are reported the chromosomes of a male patient who had symptoms and signs of Klinefelter's syndrome with diabetes mellitus and developed later polycythemia vera.

Case report. The patient was born in 1913 between a 48-yearold father and a 29-year-old mother. He married at the age of 26 years, but has no children. He is the third of five siblings, and all the siblings have children except the youngest brother who died in the World War II. There is no consanguinity in his family. Diabetes mellitus was diagnosed at the age of 50 years. At the age of 62 years, conjunctival congestion and erythema of the hands were noted. His red blood cell count was found to be markedly elevated at the age of 65 years. Then he was referred to our clinic due to polycythemia and diabetes mellitus.

On physical examinations the patient was $171 \mathrm{~cm}$ tall, weighed $65 \mathrm{~kg}$, and had an arm span of $175.5 \mathrm{~cm}$ (Fig. 1). His skin was deep red in color on the cheeks, lips, ears, tip of the nose and distal portions of the extremities. Bulbar and palpebral conjunctivae were markedly congested. He had bilateral gynecomastia and cubitus valgus, and a simian crease on the right hand. The axillary and pubic hair was scanty, and the testes were small measuring 2.5 by $1.5 \mathrm{~cm}$ on both sides. Hepatosplenomegaly was noted.

Hematological examinations revealed RBC $938 \times 10^{4} / \mathrm{cmm}, \mathrm{Hb}$ $24.0 \mathrm{~g} / \mathrm{dl}, \mathrm{Ht} 79.2 \%$ and $\mathrm{WBC} 12,400 / \mathrm{cmm}$ with $78 \%$ neutrophils and $8 \%$ eosinophils. Platelet count was $7.2 \times 10^{4} / \mathrm{cmm}$, while it was $45.3 \times 10^{4} / \mathrm{cmm}$ after a series of phlebotomy totaling $740 \mathrm{ml}$. Erythrocyte sedimentation rate was $0 \mathrm{~mm}$ in one hour. Blood chemistry 
findings were as follows: Serum alkaline phosphatase $26 \mathrm{~K}-\mathrm{A}$ units ; blood urea nitrogen $20 \mathrm{mg} / \mathrm{dl}$; serum iron $46 \mu \mathrm{g} / \mathrm{dl}$; serum protein $5.3 \mathrm{~g} / \mathrm{dl}$. Leukocyte alkaline phosphatase score was 286 (less than 100 in normal). Arterial oxygen saturation was 91\%. Fasting blood sugar was $162 \mathrm{mg} / \mathrm{dl}$, and urinary sugar excretion was $10.8 \mathrm{~g} /$ day during the treatment with 44 units of lente insulin. Urinary protein excretion was $3.0 \mathrm{~g} /$ day. Basal serum gonadotropins were elevated. Both LH and FSH showed exaggerated responses in LHRH test. Serum testosterone level was $149 \mathrm{ng} / \mathrm{dl}$. Intravenous pyelogram, electroencephalogram and respiratory function tests were normal.

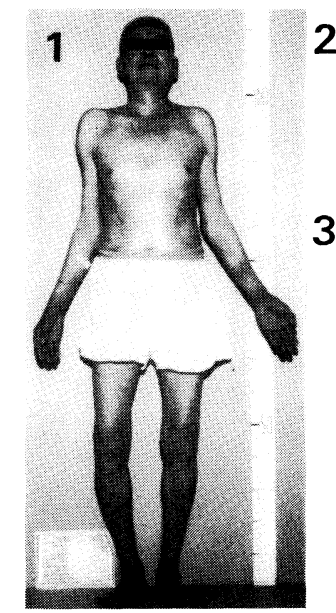

2

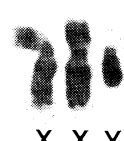

3
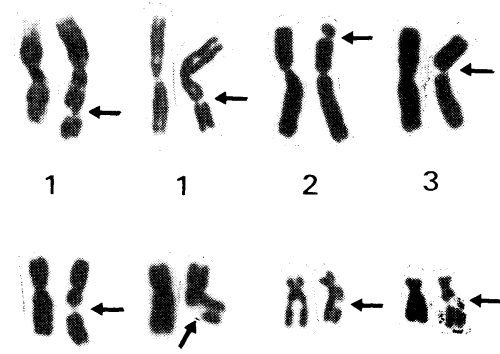

7

8

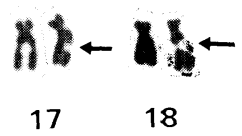

Fig. 1. Profile of the patient, at the age of 65 years.

Figs. 2-3. 2: Sex chromosomes of the patient (G-banded). 3: Breaks and gaps (arrows) in nos. 1, 2, 3, 7, 8, 17 and 18 chromosomes (Gbanded).

A trial of a single injection of $4 \mathrm{mCi}{ }^{32} \mathrm{P}$ for polycythemia vera was ineffective. Then busulfan, $4 \mathrm{mg}$ daily, was administered for 9 months, resulting in normalization of peripheral blood counts.

Cytogenetic findings. Prior to the treatment with radiophosphorus and busulfan, 21 bone marrow cells were studied and their karyotype was found to be $47, \mathrm{XY},+\mathrm{C}$. Conventional and Giemsa techniques revealed a 47,XXY karyotype characteristic of Klinefelter's syndrome in 100 cells from peripheral lymphocyte cultures (Fig. 2). Among them 9 cells showed chromosomal or chromatid gaps and breaks in nos. 1, 3, 5, 8, 15, 17, 18 and 20 chromosomes (Figs. 3-4). Buccal smears showed a single X-chromatin body in 26 out of 100 cells. During the treatment with busulfan, 30 of 100 metaphase cells from a lymphocyte culture had breaks and gaps in 
nos. $1,2,3,4,8,9,11,12,14,15,17,18$ and 20 chromosomes. The karyotype was $47, \mathrm{XXY}$. In peripheral blood samples taken 2 months after cessation of busulfan, 25 of 100 cells under study exhibited breaks and gaps in nos. 1, 2, 3, 4, 5, 7, 8, 9, 11, 15, 17, 18 and 20 chromosomes (Fig. 4).

(a)

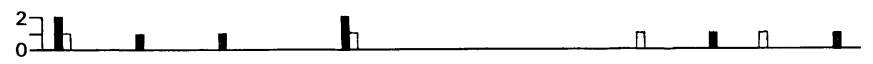

(b)
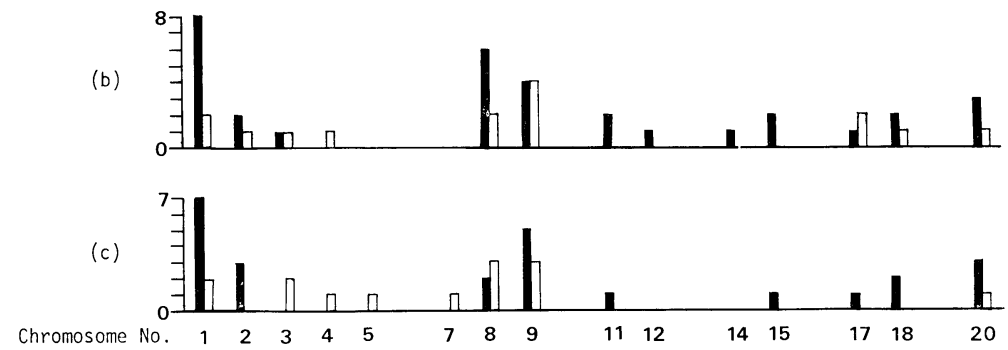

Fig. 4. Distribution of breaks ( $\square$ ) and gaps ${ }^{\circ}(\square)$. The height of the columns represents the number of chromosomes showing structural aberrations in each 100 cells. a: Before treatment, 9 cells abnormal. $\mathrm{b}$ : During treatment with busulfan, 30 cells abnormal. c: 2 months after cessation of busulfan, 25 cells abnormal.

Remarks. The diagnosis of polycythemia vera in this patient was based on marked pancytosis together with palpable spleen, the elevation of leukocyte alkaline phosphatase score and near normal arterial oxygen saturation.

The patient had signs characteristic of Klinefelter's syndrome, such as small testes and gynecomastia. This was confirmed by cytogenetical examinations finding a 47,XXY karyotype and a positive X-chromatin. A high incidence of diabetes mellitus was reported in Klinefelter's syndrome (Nielsen et al., 1969) but the association of polycythemia vera with this syndrome is rare in the literature. Geraedts et al. (1980) reported a patient with a 47,XXY karyotype who developed polycythemia vera at age below 40 and later acute myelomonocytic leukemia. In the present patient the blood cell counts were normal at the age of 68 , and he showed no signs of leukemia. Hypogonadism is known to mask some of the manifestations of polycythemia vera (Reddy et al., 1980). It is of interest that our patient manifested a marked polycythemia despite a coexisting hypogonadism.

Various clonal aberrations have been repeatedly reported in patients with polycythemia vera (Mitelman and Levan, 1976; Rowley, 1977; Sandberg, 1980; Testa et al., 1981). The present patient showed no detectable clones, but breaks and gaps were found to 
occur in chromosomes of groups A, B, C, D, E and F, before therapy. The increase in frequency of these aberrations in this patient after therapy might have been induced by radiophosphorus treatment (Barnes et al., 1969) and/or by busulfan administrations (Honeycombe, 1978).

Acknowledgement. We are grateful to Professor Emeritus, Dr. Sajiro Makino, M. J. A., for improvement of the manuscript with valuable advice.

\section{References}

Barnes, C. A., Holmes, H. L., and Ilbery, P. L. T.: Aust. Radiol., 13, 396-417 (1969).

Geraedts, J. P. M., Mol, A., Briet, E., Hartgrink-Groeneveld, C. A., and Den Ottolander, G. J.: Lancet, i, 774 (1980).

Honeycombe, J. R.: Mutat. Res., 57, 35-49 (1978).

Mitelman, F., and Levan, G.: Hereditas, 82, 167-174 (1976).

Nielsen, J., Johansen, K., and Yde, H.: J. clin. Endocrinol. Metab., 29, 1062-1073 (1969).

Reddy, G. N. K., Nagar, S., and Trubowitz, S.: J. med. Soc. N. J., 77, 430-432 (1980).

Rowley, J. D.: Proc. Natl. Acad. Sci., 74, 5729-5733 (1977).

Sandberg, A. A.: The Chromosomes in Human Cancer and Leukemia. Elsevier North Holland, New York (1980).

Testa, J. R., Kanofsky, J. R., Rowley, J. D., and Baron, J. M.: Hum. Genet., 57, 165-168 (1981). 